\title{
As Construções Microgenéticas e o Design em Robótica Educacional *
}

\author{
Daniel de Queiroz Lopes < daniel.lopes@ufrgs.br > \\ Lea da Cruz Fagundes < leafagun@ufrgs.br > \\ Programa de Pós-Graduação em Informática na Educação \\ Universidade Federal do Rio Grande do Sul (UFRGS) \\ Av. Paulo Gama, 110 - prédio 12105 - $3^{\circ}$ andar sala 332 \\ 90040-060 - Porto Alegre - RS - Brazil
}

Resumo. A partir da Epistemologia Genética de Jean Piaget, analisamos o papel do design nas construções microgenéticas dos esquemas conceituais envolvidos em projetos realizados em ambiente de robótica educacional. Discutimos a atividade de design como elemento necessário ao processo criativo, capaz de sustentar o desenvolvimento de ações com alto grau de significação em relação aos projetos desenvolvidos. Apontamos a compreensão acerca das construções microgenéticas como fundamental para qualificar as aprendizagens e para caracterizar uma proposta construtivista, fornecendo subsídios teóricos que justifiquem a implementação de projetos na área de robótica educacional.

Palavras-chave: robótica educacional, construtivismo, epistemologia genética.

Abstract. Using the framework of Piaget's Genetic Epistemology, in this study we analyze the role of design in contextualized projects development of educational robotics. We also analyze the microgenesis of conceptual schemas construction. We discuss design activity as basis to improve the creative process and to support the development of actions with a high signification level about the developed projects. We recognize the microgenetic constructions in order to qualify the learning process and to define a constructivist proposal to the empowerment of educational robotics projects.

Keywords: robotics on education, constructivism, genetics epistemology.

\section{Introdução}

\section{A robótica educacional construtivista}

Dentre os diversos recursos tecnológicos aplicados a educação, pode-se dizer que a robótica tem sido uma das que mais tem avançado em termos de inovações. No entanto, apesar destes avanços, apenas uma ínfima parcela das instituições educacionais tem se apropriado destes recursos. Com isto, a maior parte do que está sendo produzido em termos de referencial teórico-metodológico não chega ao conhecimento de professores e alunos.

\footnotetext{
* O presente artigo é parte integrante de estudo piloto do projeto de tese em andamento do doutorando Daniel de Queiroz Lopes, PPGIE/UFRGS. 
A robótica muitas vezes é compreendida como matéria de formação técnica, aplicável apenas no ensino profissionalizante de níveis médio ou superior. Porém, existe uma aplicação para a robótica que leva em conta o potencial que esta área pode alcançar na educação de jovens em idade escolar: é a Robótica Educacional - RE.

Desde que Resnick e seus colegas do Media Lab, sob orientação de Seymour Papert, desenvolveram, no Massachusetts Institute of Technology (MIT), a interface LEGO $^{\circledR} /$ Logo (Resnick \& Ocko, 1991), posteriormente, os "tijolos programáveis" (Resnick, Martin, Sargent e Silverman, 1996) e, mais tarde, a criação de sua versão comercial pela divisão educacional da LEGO $^{\circledR}$, a atividade de design e a de programação de robôs têm deixado de ser matéria exclusiva das faculdades de informática, engenharia mecânica e mecatrônica. A facilidade de montagem e programação dos robôs através de conjuntos de peças articuláveis, bem como as interfaces intuitivas de programação, podem ser apontadas como fatores que hoje colocam a robótica num campo acessível aos propósitos educacionais. Convém acrescentar que grande parte desses desenvolvimentos tecnológicos do Media Lab vieram acompanhados de um referencial teórico consistente, através dos pressupostos construcionistas de Papert (Papert, 1994; Ackermann, 2001). A partir da Epistemologia Genética, Papert propõe que a aprendizagem se dá mais efetivamente na construção pessoal de artefatos significativos (como programas de computador, animações, ou robôs). Esta efetividade da aprendizagem na construção de robôs foi comprovada em vários estudos, como os do Media Lab (Resnick \& Ocko, 1991; Hancock, 2001), do Laboratório de Estudos Cognitivos/IP/UFRGS (Lopes \& Fagundes, 1995), na UNICAMP/NIED (D'Abreu, 1993), entre outros. Estes estudos comprovaram que a atividade de programação, de design e de depuração de protótipos permitem ao sujeito enriquecer seus esquemas de significação com novos esquemas de representação lógicomatemáticos, lingüísticos e estéticos, elementos essenciais da aprendizagem.

No entanto, nem sempre os princípios norteadores do construtivismo são levados em consideração no que se refere a projetos de RE. É bastante comum encontrar projetos que limitam a atividade dos sujeitos à montagem a partir de modelos prontos, acabados, nos quais todos os erros e estratégias estão compensados pelo autor original ou previstos nas instruções de montagem. Tais projetos carregam o princípio da aprendizagem através da cópia e da transmissão, ou, ainda, acreditam que, para uma proposta construtivista, basta que tais modelos estejam contextualizados na forma de problemas do cotidiano. Ainda assim, os problemas são sempre postos a priori, metáforas pré-concebidas de fenômenos naturais, sociais ou industriais.

Considerando o problema acima, e que existe um quadro teórico de referência consistente e abrangente, o presente artigo apresentará alguns pressupostos relativos ao construtivismo, analisando principalmente o papel do design para as construções microgenéticas dos esquemas conceituais envolvidos em projetos de robótica educacional. Discutirá, assim, a importância da atividade de design como elemento norteador de projetos em RE fundamentados nos princípios construtivistas de Piaget.

\section{Material e métodos}

O ambiente de RE no qual se desenvolveu o presente estudo, utilizou-se dos kits LEGO $^{\circledR}$ Mindstorms, (peças, tijolo programável) e o software ROBOLAB $^{\circledR}$ para programação dos protótipos.

Participaram do estudo estudantes de $5^{\mathrm{a}}$ a $8^{\mathrm{a}}$ séries de escola particular de classe média, com faixas etárias entre os 10 e os 13 anos. Foram realizadas sessões semanais de aproximadamente $2 \mathrm{~h}$ de duração, duas vezes por semana, por um período mínimo de 
4 meses. As intervenções investigativas do pesquisador tomaram por princípio o método clínico de Piaget.

\section{Resultados e discussão}

\section{O design em robótica educacional}

Em termos gerais, a robótica educacional pode ser compreendida como um conjunto de recursos que visa o aprendizado científico e tecnológico integrado às demais áreas do conhecimento, utilizando-se de atividades como design, construção e programação de robôs. Diferencia-se do aprendizado técnico em robótica no sentido de não priorizar o domínio dos instrumentos e códigos de programação em função de uma demanda profissionalizante, demanda esta que normalmente se utiliza de ferramentas específicas para uma produção de artefatos em larga escala ou industriais. Ao invés disso, o que estamos propondo é que a RE tenha como foco principal promover o design e a invenção de protótipos que satisfaçam uma demanda específica, localizada e identificada com as demandas particulares de aprendizagem de jovens e adultos.

Além da atividade de design, os projetos em robótica educacional encontram nas estratégias de resolução de problemas um elemento complementar e necessário: a atividade de análise. Enquanto a atividade de análise envolve a decomposição de problemas em subproblemas mais simples, geralmente com o suporte de algum conjunto de regras formalizadas, a atividade de design cria e define, na concepção do que será produzido, a ordem e a natureza dos problemas. Porém, na atividade de design os problemas geralmente estão pouco estruturados, já que é parte da tarefa do designer ir definindo seus próprios problemas à medida que seu projeto é desenhado. Com isso, ao invés de buscar soluções otimizadas, os designers geralmente buscam soluções satisfatórias. (Simon 1969; apud Resnick \& Ocko 1991)

Para Resnick e Ocko (1991), o design desempenha um papel central na atividade humana e, portanto, na educação. Porém, para muitos educadores, a natureza pouco estruturada das atividades de design as torna inapropriadas para uma sala de aula, pois são difíceis de gerenciar e avaliar. Disso resulta que raramente os estudantes têm a oportunidade de construir, criar ou inventar.

Da mesma forma, se a robótica educacional for concebida apenas como um recurso para a análise de "situações-problema" a partir de experiências prédeterminadas e controladas, poderá se tornar em um aparato tecnológico pouco instigador e limitado, já que as "situações-problema" irão sempre depender da criatividade e capacidade de entendimento de quem propõe os problemas.

Ao contrário, para que a robótica possa se constituir como um recurso tecnológico inovador em termos curriculares, os elementos design, criação e invenção devem ser tomados como chaves, já que é a partir deles que os sujeitos definirão seus próprios problemas e desenvolverão suas estratégias para construção de seus protótipos, e não o inverso. Sob essa perspectiva, ampliam-se as possibilidades na medida que os caminhos tomados para resolver um problema serão sempre uma construção por parte dos sujeitos envolvidos nas atividades, cujas soluções poderão aparecer de diversas formas, bem sucedidas ou não. Assim, ao invés de repetidores de problemas e soluções, os sujeitos passam a experimentar a condição de verdadeiros inventores.

\section{As construções microgenéticas e o design em robótica}

Dentro da Epistemologia Genética de Jean Piaget, encontramos a análise das construções microgenéticas como um elemento essencial para a compreensão das 
transformações de esquemas elementares. Trabalhos sobre tais transformações já foram publicados (Piaget \& Inhelder 1971; Piaget 1987; Inhelder [et al.], 1996) e podem servir de referência para se pensar como se dá a aprendizagem em robótica educacional, particularmente, as transformações dos sistemas de esquemas envolvidos na atividade de design, construção e programação.

Um estudo de M. Saada-Robert sobre "A construção microgenética de um esquema elementar" (Saada-Robert, 1996) traz uma contribuição importante para o entendimento das microgêneses na resolução de problemas. O autor analisa os três status de um sistema de esquemas (rotina, primitiva e procedimento), as mudanças de significado destes esquemas e suas respectivas transformações de controle referentes à organização das ações e dos significados em função de um dado objetivo. Baseando-nos nestes conceitos, fundamentamos diversas análises acerca do design em robótica educacional, como se poderá observar a seguir.

Para que a robótica assuma um papel inovador em educação, o design e a invenção devem assumir um papel central. Se entendermos que o design passa necessariamente pela modelagem, é pressuposto que o sujeito, a fim de se lançar na construção de algum protótipo, parta de um saber ou modelo de referência próprios. No que concerne as microgêneses, parte-se sempre da hipótese de que um conhecimento prévio ativado pelo sujeito ao resolver um problema é um conhecimento difuso, indiferenciado em relação a totalidade do seu objetivo. Estudos anteriores apontam para essa indiferenciação inicial na modelagem de protótipos (Lopes \& Fagundes, 1995), nos quais se pode perceber que, ao desenhar seus protótipos, os sujeitos não apresentam todos os elementos mecânicos e lógicos articulados. É assim que, quando os sujeitos se propõem, por exemplo, a construir um carro, quase sempre partem da reprodução de um modelo real, de um "carro em geral", identificando uns poucos elementos que vêm a qualificar o seu protótipo como tal (rodas, carroceria, portas, cano de descarga, etc.), e dificilmente aparecem elementos mecânicos vitais para o funcionamento do mesmo (motor, engrenagens e sistemas de transmissão, etc.).
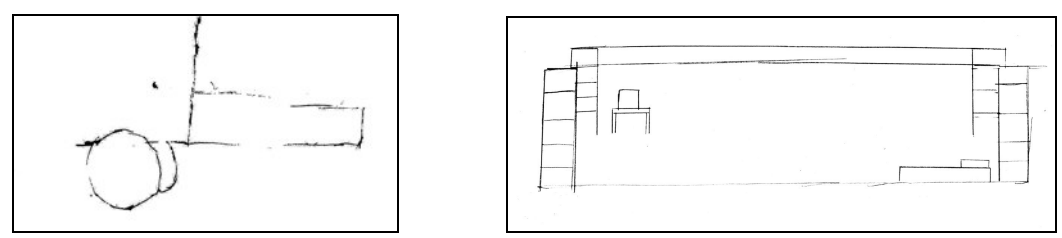

Figura 1. Desenho dos protótipos "Carro" e "Casa"

Nos exemplos da Figura 1, apresentamos o desenho de dois grupos de estudantes de $6^{\text {a }}$ série do Ensino Fundamental, de 11 anos de idade, que queriam construir, respectivamente, um carro e uma casa.

À primeira vista, este modelo genérico inicial, em bloco, com poucos detalhes, pareceria óbvio e esperado, já que o problema de se construir "um carro" e "uma casa" não está posto em termos de seu funcionamento ou de suas especificidades. Porém, por se tratar de uma atividade de RE, os próprios sujeitos acrescentaram aos seus projetos adjetivos que indicam uma diferenciação conceitual e idealizada: o carro deveria ser "um carro inteligente" e a casa deveria ser "viva, do futuro".

Quando apareceram as primeiras diferenciações em relação a representação que os sujeitos tinham de um objeto real em relação a um objeto idealizado, os problemas foram surgindo, passando a integrar e a conduzir sua atividade em relação à criação ou invenção de modelos que pudessem dar conta de novos possíveis. Ao serem questionados sobre como funcionariam seus protótipos, os sujeitos acrescentaram aos adjetivos "inteligente" e "viva" suas razões ou "porquês". Desde então, passaram a definir o problema inicial a ser resolvido: "o carro é inteligente porque segue uma luz" 
e "a casa é viva porque é automática" - portas que se abrem por controle, luzes que piscam, etc. Estes "porquês", ao mesmo tempo que explicavam seus projetos, constituíram-se em problemas totalmente integrados com os objetivos dos sujeitos, condição fundamental para que seja possível coordenar ações com elevado grau de significância para os mesmos. Com a abertura para novas possibilidades, alguns dos elementos mecânicos passaram a integrar os modelos (motores, engrenagens, botões, sensores, etc.), inicialmente, de forma desarticulada ou inapropriada, mas que, sofrendo sucessivas regulações em relação ao objetivo, acabaram por integrar o modelo inicialmente idealizado. O modelos iniciais apresentados (como na Figura 1), por sua vez, também se alteraram em função das transformações retroativas, isto é, as modificações dos sujeitos em relação aos resultados de suas ações sobre os objetos (no caso, peças LEGO $^{\circledR}$, motores, engrenagens, etc). O produto final (Figura 2) mostra como as alterações no design produziram novas possibilidades lógicas e estéticas, que também puderam ser evidenciadas através dos elementos da programação dos protótipos e das explicações que os estudantes deram acerca do seu funcionamento - como será apresentado mais adiante.

O exemplo a seguir (Figura 2) mostra como a invenção destes modelos e a criação de novas possibilidades pode abrir caminho para a construção de novos conhecimentos. Porém, para que seu conhecimento se torne uma tecnologia aplicável, o sujeito precisará integrar seu modelo (ex.: sua "idéia de carro") aos procedimentos (ex.: "funcionamento do carro"), e, para tanto, precisará efetuar uma dupla passagem: do difuso ao preciso e do disperso ao unitário - é esta dupla passagem que consistirá numa evidência de construção microgenética.

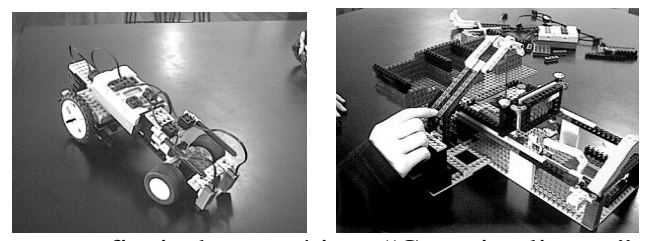

Figura 2. As versões finais dos protótipos "Carro inteligente" e "Casa viva"

\subsection{A definição e escolha de rotinas}

Ainda acerca das transformações microgenéticas, pode-se perceber no design, depuração e programação dos protótipos em robótica que (1) as mudanças de significado e (2) as transformações de controle são importantes campos conceituais para serem analisados.

Com relação ao primeiro campo, a definição e escolha de rotinas pelos sujeitos é, inicialmente, essencial e se constitui como um primeiro processo de adaptação do sujeito em relação ao problema. Esta escolha se dá a partir da ativação de esquemas familiares ao sujeito, simplesmente pela sua pertinência em relação a situação e objetos envolvidos. É assim que uma casa, inicialmente, possui paredes, portas e janelas e o carro, essencialmente, eixos e rodas.

Para demonstrar esse processo, pode-se observar o exemplo a seguir, envolvendo o mesmo grupo que estava construindo a "Casa viva". Em dado momento, o grupo idealizou uma porta automática, que abriria com o apertar de um botão. Como solucionar o problema de abrir esta porta automaticamente? Com o objetivo de ativar esquemas de referência próprios dos sujeitos, perguntou-se a eles como faziam para abrir uma porta, e solicitou-lhes que demonstrassem. Sem problema algum, responderam o que normalmente se faz para abrir uma porta: utiliza-se o braço e a mão na maçaneta e abre-se a porta. Através da observação e análise da ação de abrir a porta, 
perceberam que o braço era a ferramenta principal desta ação, e partiram para a construção de um sistema que simulasse o movimento do braço ao abrir a porta, sistema que culminou com o protótipo apresentado na Figura 3.

Apesar do grupo não estar familiarizado com o material (Kits LEGO ${ }^{\circledR}$ Mindstorms) e estar participando pela primeira vez de atividades de RE, rapidamente implementaram uma solução para o problema apresentado. Esta solução foi possível em função do alto grau de significância do modelo que possuíam (o próprio braço, no caso) para com o problema que se apresentava.

O problema já estaria resolvido se não fosse a discussão que o grupo teve em relação ao modo de funcionamento da casa. Esta "Casa viva", além de abrir a porta automaticamente, também possuiria outras características. O grupo resolveu que, por segurança, a porta deveria ser aberta por alguém de dentro da casa, e a "campainha", ao ser acionada, faria piscar uma luz e tocar um som, para que tanto cegos quanto surdos pudessem perceber que alguém queria entrar. Estas decisões em grupo são fundamentais no sentido de favorecer a cooperação, já que o problema precisa estar com alto grau de significação para todos, a fim de que a coordenação das ações possam ocorrer em conjunto e não apenas isoladamente ou individualmente.

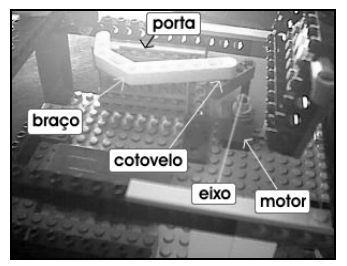

Figura 3. "Casa viva" - sistema de abertura automática da porta construído a partir da observação do movimento de um braço abrindo uma porta

Durante a etapa da programação, pode-se observar como este tipo de atividade favorece o enriquecimento dos sistemas de significação dos sujeitos. A fim de implementar o funcionamento acima descrito, o grupo iniciou explorando o modo de programação do ROBOLAB ${ }^{\circledR}$. Num primeiro momento, usaram um modelo simples (Figura 4) que apenas ligava a lâmpada por 5 segundos. Este modelo possuía uma lógica básica, bem elementar, para o controle dos protótipos. Esta lógica era baseada no esquema LIGA $\rightarrow$ ESPERA $\rightarrow$ DESLIGA (LED). Ao longo da construção do programa, pode-se observar a utilização deste mesmo esquema até que chegassem num resultado satisfatório e o protótipo da "Casa viva" funcionasse da forma idealizada.

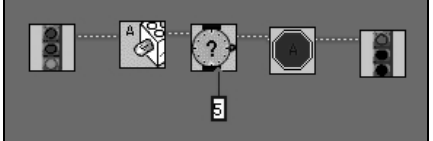

Figura 4. Programa simples que liga uma lâmpada conectada à porta "A" do RCX, espera por 5 segundos e desliga a mesma lâmpada

$\mathrm{Na}$ Figura 5, pode-se observar o esquema LED em várias etapas e o maior trabalho do grupo foi testar e programar os tempos de espera entre uma ação e outra. Assim, calcularam quanto tempo o motor deveria ficar ligado para que a porta abrisse e fechasse totalmente. Este tempo de espera foi determinado pelas próprias condições mecânicas do sistema elaborado (força do motor, ângulo da alavanca, etc) e não chegou a ser formalizado pelos sujeitos. Porém, um exemplo que revela a total integração deste esquema LED com a representação do funcionamento da casa foi quando o grupo discutiu quanto tempo a porta deveria ficar aberta. $\mathrm{O}$ grupo estabeleceu que, quando o sensor-de-toque 2 fosse acionado, a porta deveria permanecer aberta por quatro segundos e fecharia automaticamente. Para o grupo, este seria o tempo de espera 
suficiente até que uma pessoa entrasse na casa. Observa-se que, desta vez, o tempo não foi determinado pelos elementos mecânicos envolvidos na abertura da porta, mas sim por uma exigência dos próprios sujeitos, que consideraram o tempo razoável em função da experiência de cada um.

Pelos resultados observados, constata-se que, além dos elementos mecânicos e estéticos envolvidos no design e depuração dos protótipos, a atividade de programação contribuiu para a abertura de novas possibilidades, no momento em que se constitui como objeto comum da atividade dos sujeitos e sobre o qual o grupo coordena suas ações no sentido de fazer funcionar seus protótipos. E é exatamente esta abertura para novas possibilidades que motiva os sujeitos a aprender, buscar soluções para problemas e situações próprias, isto é, com um alto grau de significância.

Tanto nas etapas de modelagem e montagem dos protótipos quanto na de programação, demonstra-se a importância da escolha das rotinas e procedimentos pelos próprios sujeitos e, principalmente, que possam de alguma forma ser familiares a eles, ou seja, possam ser ativadas a partir de seus próprios esquemas.

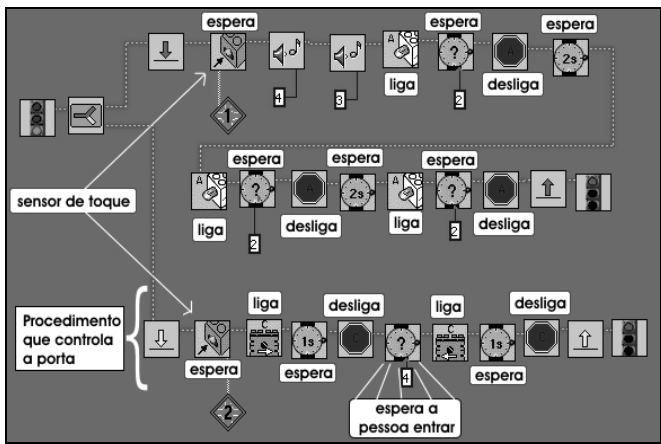

Figura 5. Programa que controlava o funcionamento da "Casa viva"

\subsection{A utilização de modelos de protótipos}

Como foi afirmado anteriormente, nas atividades de construção de protótipos em RE, é comum pensar que basta aos sujeitos copiar modelos prontos para assimilar novos conceitos. Este equívoco é comum e facilmente demonstrável, como apresentaremos a seguir.

Um grupo de 4 sujeitos, estudantes de $5^{\text {a }}$ série, com 10 anos de idade, queriam construir um carro que, além de se movimentar para frente e para trás, virasse as rodas dianteiras com um sistema de direcionamento semelhante ao de um automóvel comum. Foi fornecido aos sujeitos uma revista que continha um modelo de direcionamento das rodas como o da Figura 6. A revista apresentava o modelo em partes, compondo blocos numa sequiência de montagem até o produto final. Os sujeitos montaram conforme as instruções, porém, fizeram uma alteração importante e reveladora que demonstra como este modelo ainda não estava integrado como uma solução possível para o problema de "virar as rodas" do carro.

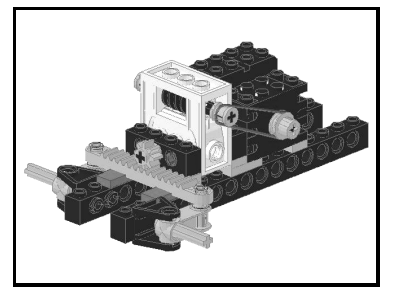

Figura 6. Modelo de revista para sistema de direcionamento das rodas 
$\mathrm{Na}$ Figura 7, pode-se observar no protótipo construído pelos sujeitos que o modelo copiado da revista foi posicionado na parte traseira do carro. $\mathrm{O}$ grupo inferiu que este modelo serviria para movimentar o carro (tração) e não para controlar a sua direção. Para a surpresa dos sujeitos, ao ligarem o motor num alimentador de testes, o carro virou as rodas ao invés de se movimentar. A partir de então, passaram a construir, agora sim, a parte traseira do carro, e o modelo da revista foi integrado ao projeto como uma solução viável em relação ao problema de virar as rodas do carro.

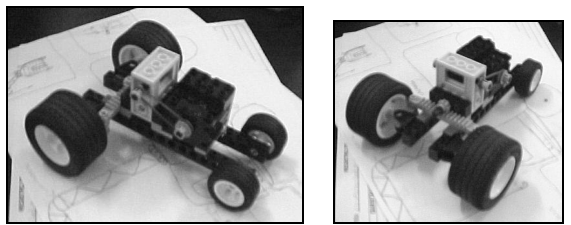

Figura 7. Protótipo inicial de carro produzido a partir da apropriação de modelo

O maior problema nas montagens a partir de modelos prontos é que todos os erros e problemas já foram testados e corrigidos, fazendo com que o sujeito apenas observe o resultado, quase sempre bem sucedido em função da riqueza de detalhes oferecidos para a montagem. Nestes casos, os modelos acabam permanecendo como uma representação em bloco, pouco generalizável, rotinas não componíveis ou articuláveis o suficiente para enriquecer os sistemas de esquemas do sujeito e serem aplicados em outras situações. Isto não quer dizer que os modelos de montagem não possam ser utilizados, mas que este tipo de atividade não é suficiente para desenvolver a criatividade do sujeito - talvez, até, nem seja necessária.

Para muitos educadores, a função de apresentar um modelo aos alunos é suficiente para transmitir um sistema de significações postas a priori. Como se pode perceber no caso do modelo acima, foi preciso a ação $\boldsymbol{e}$ a análise do resultado dessa ação pelos sujeitos a fim de que o modelo pudesse ser efetivamente aplicado como uma solução para o problema. Mesmo assim, não se pode afirmar que este modelo tenha sido assimilado pelos sujeitos, pois ele ainda aparece em bloco, como uma solução para um problema específico, podendo ser igualmente rejeitado em bloco numa outra situação semelhante.

\subsection{De rotina à primitiva}

Uma primitiva é sempre ajustável a novas situações, enquanto que uma rotina funciona somente em blocos não-componíveis ligadas a objetos específicos. Entre rotina e primitiva, opera-se um segundo processo de adaptação: após a escolha das rotinas ligadas à situação problema ou função dos objetos, agrega-se a significação em função da solução. Com isto, uma rotina poderá ser rejeitada em função de sua não-significação em relação ao problema proposto. Esta operação entre rotina e primitiva "constitui um elemento de base da construção microgenética, sendo reconhecida como elementochave da resolução e condição necessária para a solução." (Saada-Robert, 1996; p. 112)

O que se tem percebido na conduta dos sujeitos é que tais modelos apresentados prontos continuam sendo aplicados em bloco, como esquemas que servem para resolver problemas específicos. Por exemplo, o sistema $\{$ motor+eixo $\rightarrow$ engrenagem $\rightarrow$ eixo+roda\} é um sistema de transmissão de movimento que acaba por ser bastante útil em diversas situações. Tais sistemas acabam se tornando familiares aos sujeitos, ligados a um controle ascendente do significado em bloco que este esquema possui em relação ao todo e, enquanto rotina, funciona na maior parte das vezes.

No entanto, quando estas rotinas não são adequadas aos novos problemas, devem sofrer transformações e adaptações que, ao mesmo tempo que enriquecem os 
esquemas do sujeito, revelam se o sujeito foi capaz ou não de assimilar todos os elementos que compõem as partes integrantes de um dado modelo, bem como as relações entre essas partes.

\subsection{De primitiva à procedimento}

Uma ação primitiva isolada, apesar de necessária, ainda não tem o poder de oferecer uma solução para um dado problema. Saada-Robert (1996) se utiliza do termo procedimento-tipo, ou unidade de procedimento manipulável, que, enquanto bloco, poderá servir de rotina ou primitiva num outro contexto. Ou seja, a ação (primitiva) de conectar engrenagens seguramente servirá para propósitos diversos, desde que o sujeito, na atualização de seus esquemas frente a um novo problema, gere novas composições e modelagens que mantenham sua ação com um alto grau de significação em relação à solução do problema (status de primitiva, como no exemplo de programa que usa as primitivas LED - Figura 5). Do contrário, se tais ações aparecerem indiferenciadas (status de rotina) poderão ser rejeitadas em bloco caso o resultado não seja satisfatório.

Tal rejeição pode freqüentemente ser entendida como um bloqueio dos sujeitos na resolução de um problema, pois muitas ações necessárias são descartadas pelo status que o sujeito lhe confere e não propriamente pelo conteúdo da ação. "O bloqueio pode ser vencido quando o sujeito modifica o significado de sua ação, sem rejeitar a ação em si”. (Ibidem.; p. 115). Um exemplo dessas mudanças de significado da própria ação pode ser observado no exemplo do grupo anteriormente apresentado, que utilizou um modelo de direcionamento das rodas (Figuras 4 e 5). Apesar da constatação de que o efeito produzido (virar as rodas) não fora o esperado (deslocar o carro), o modelo não foi descartado, mas sim incorporado ao protótipo de forma mais adequada (Figura 8).

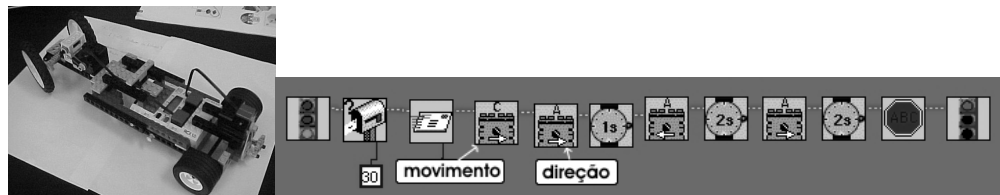

Figura 8. O protótipo do "Carro" e o programa que o fazia se movimentar em "zigue-zague"

Num outro momento, este mesmo grupo criou um programa para controlar o carro (Figura 8) e este programa deveria fazer com que o carro se movimentasse em "zigue-zague" após receber uma mensagem de outro protótipo. $\mathrm{O}$ motor ligado à porta "C" controlaria o movimento do carro e o ligado à porta "A" controlaria a direção do mesmo, produzindo o "zigue-zague". Porém, ao testar o programa, não notaram que os fios que conectavam os motores às portas " $A$ " e " $C$ " do RCX estavam invertidos, o que fez com que o carro se movimentasse para frente e para trás. Imediatamente, ao invés de supor que o problema pudesse estar na programação, o grupo constatou o problema e rearranjou a ligação dos fios. Foi uma ação precisa, revelando que os sujeitos foram capazes de coordenar seus esquemas de ação, representados pelo programa, sem simplesmente descartá-los e inferir sobre os resultados dessa ação, resolvendo o problema.

\section{Conclusões}

Compreender as transformações microgenéticas torna-se fundamental para qualificar as aprendizagens e caracterizar um modelo construtivista. Para o caso de projetos em RE, fornece subsídios teóricos que justificam a implementação de tais projetos, além de subsidiar inovações curriculares adequadas aos novos recursos tecnológicos e as demandas sócio-educacionais. 
Como se pode constatar, os processos acima apresentados e explicados com base na epistemologia genética, principalmente acerca das microgêneses, fornecem elementos importantes para uma Robótica Educacional construtivista. A atividade de design foi apresentada como elemento necessário ao processo criativo, isto porque é capaz de sustentar o desenvolvimento de ações com alto grau de significação em relação aos problemas que surgem ao longo da implementação de protótipos. Dentre os processos de construção envolvidos, o estabelecimento de uma rotina pelo sujeito e a sua passagem à primitiva, e a conseqüente composição das diversas primitivas em procedimento, foram apresentados como elementos reveladores das transformações microgenéticas que ocorrem no design, depuração e programação em Robótica Educacional.

\section{Referências}

ACKERMANN, E., Piaget's Constructivism, Papert's Constructionism: What's the difference? [An extended version of this paper appears in French in] Constructivisms: Usages et Perspectives en Education (Volume 1 et 2.) Geneva: SRED/Cahier 8. pp. 85-94, 2001. Disponível em $<\mathrm{http}$ ://learning.media.mit.edu/content/publications/EA.Piaget\%20_\%20Papert.pdf>. Acesso em 13 nov. 2006

D'ABREU, J. Vilhette V. LEGO-Logo: explorando o conceito de design. In: VALENTE, J. Computadores e Conhecimento: repensando a educação. UNICAMP/NIED: Campinas, 1993.

HANCOCK, C. Children's Understanding of Process in the Construction of Robot Behaviors. In: Varieties of Programming Experience. AERA 2001, Seattle. Disponível em $<$ http://llk.media.mit.edu/papers/uproc/uproc.html>. Acesso em 13 nov. 2006.

LOPES, D. \& FAGUNDES, L. (1995). "O desenvolvimento de noções de mecânica por surdos num ambiente informatizado", In: Simpósio Brasileiro de Informática na Educação, Anais. SBC UFSC - EDUGRAF, Florianópolis.

PAPERT, S. (1994). A Máquina das Crianças: repensando a escola na era da informática. Artes Médicas, Porto Alegre.

PIAGET, J. (1987) O nascimento da inteligência na criança. Zahar Editores, Rio de Janeiro.

PIAGET, J. \& INHELDER, B. (1971). Gênese das Estruturas Lógicas Elementares. Zahar Editores, Rio de Janeiro.

INHELDER, B. [et al.] O desenrolar das descobertas da criança. Artes Médicas, Porto Alegre, 1996.

RESNICK, M., and OCKO, S. LEGO/Logo: Learning Through and About Design. Epistemology and Learning Group, MIT: Media Laboratory. Cambridge. MA. Disponível em <http://llk.media.mit.edu/papers/ll.html>. Acesso em: 13 nov. 2006.

RESNICK, M., MARTIN, F., SARGENT, R., and SILVERMAN, B. Programmable Bricks: Toys to Think With. IBM Systems Journal, vol. 35, no. 3-4, pp. 443-452. Disponível em $<$ http://researchweb.watson.ibm.com/journal/sj/353/sectionc/martin.html>. Acesso em 13 nov. 2006.

SAADA-ROBERT, M. A construção microgenética de um esquema elementar, In: INHELDER, B. [et al.] O desenrolar das descobertas da criança. Artes Médicas, Porto Alegre, 1996. 